\title{
Vitamin D Improves Oral Glucose Tolerance and Insulin Secretion in Human Diabetes
}

\author{
Namala Raghuramulu, ${ }^{1, *}$ Manchala Raghunath, ${ }^{1}$ Suresh Chandra, ${ }^{1}$ \\ Kumar Binod SAHAY, ${ }^{2}$ and Prakash Chandra GUPTA ${ }^{3}$ \\ ${ }^{1}$ National Institute of Nutrition, ICMR, Hyderabad 500007 , \\ Andhra Pradesh, India \\ ${ }^{2}$ Osmania General Hospital, Hyderabad 500 001, \\ Andhra Pradesh, India \\ ${ }^{3}$ Gandhi Hospital, Secunderabad 500 003, \\ Andhra Pradesh, India
}

(Received January 9, 1992)

\begin{abstract}
Summary Glucose intolerance and impaired insulin secretion in vitamin D deficiency, and altered vitamin $D$ metabolism in streptozotocin- or alloxan-induced diabetes, are well established in experimental animals. No such data are available in humans. The present study was conducted on a group of uncontrolled diabetic patients: those with non-insulin-dependent diabetes mellitus (NIDDM: 42) and those with insulin-dependent diabetes mellitus (IDDM: 6). After an initial oral glucose tolerance test, each subject was given one intramuscular injection of vitamin D (vitamin $\mathrm{D}_{3}: 300,000 \mathrm{IU}$ ), and the oral glucose tolerance test was then repeated after 4 weeks.

Administration of vitamin D resulted in a significant improvement in the oral glucose tolerance, serum calcium, and also glucose-stimulated increase in serum insulin levels. Possible mechanism(s) of this beneficial effect of vitamin D on human diabetes is discussed.
\end{abstract}

Key Words: vitamin D, IDDM, NIDDM, glucose tolerance, insulin secretion

Association of osteoporosis with long standing, uncontrolled diabetes mellitus has been known for a long time [1]. Interestingly, administration of insulin corrected the bone abnormalities to a certain extent [2], thereby implying a role of insulin in bone metabolism. Though not unequivocal, some available evidence suggested an association between hypocalcemia and hyperglycemia in secondary

*To whom correspondence should be addressed. 
diabetes [3].

Cholecalciferol (vitamin $\mathrm{D}_{3}$, vitamin $\mathrm{D}$ ) is a prohormone and its active metabolite, 1,25-dihydroxy vitamin $\mathrm{D}\left[1,25(\mathrm{OH})_{2} \mathrm{D}\right]$, is now considered to be a hormone. It is a known regulator of calcium homeostasis and is now established to be essential for normal secretion of insulin in experimental animals $[4,5]$. Further, glucose tolerance has been demonstrated to be impaired in vitamin $\mathrm{D}$-deficient rats and rabbits and normalized by treatment with $1,25(\mathrm{OH})_{2} \mathrm{D}[6,7]$.

Despite overwhelming evidence in experimental animals suggesting the essentiality of vitamin D for normal insulin secretion and glucose metabolism, there are no such observations in human diabetes mellitus. Hence, the present investigation was carried out in patients with diabetes mellitus to evaluate the effects of vitamin D administration on glucose tolerance and insulin secretion.

\section{SUBJECTS AND METHODS}

Forty-eight, adult-onset diabetes mellitus patients of both sexes in the age group of 30-60 years, who attended the out-patient diabetic clinic of a medical college hospital comprised the subjects of the study. Six of the subjects had type I diabetes (insulin-dependent diabetes mellitus, IDDM) and the other forty two were of type II diabetes (non-insulin-dependent diabetes mellitus, NIDDM). The study was cleared by the ethics committee of the institute and hospital, and prior consent of the patients was obtained. The patients were on their home diets and continued their usual medical treatment throughout the duration of the study.

After an overnight fast, venous blood was drawn from each subject, who was then given an oral dose of $75 \mathrm{~g}$ of D-glucose dissolved in water [8]. This was followed by the collection of venous blood, 1 and $2 \mathrm{~h}$ later. Each subject was then administered, intramuscularly, 300,000 IU of vitamin D (Duphar Interfran, Bombay, India) and was asked to continue the usual medical treatment and dietary regimen. Oral glucose tolerance test (GTT) was repeated in each subject 4 weeks after the administration of the vitamin $\mathrm{D}$.

Glucose was estimated in the deproteinized whole blood samples by the method of Ashwell [9]. Serum insulin was determined (in 6 NIDDM patients only) with a radioimmunoassay kit supplied by Bhaba Atomic Research Centre, Bombay, India. Total blood glucose $(\mathrm{mg} / \mathrm{dl})$ and total serum insulin $(\mathrm{mU} /$ liter) were calculated as: $\left(G_{0}+G_{1}+G_{2}\right) / 3$ and $\left(I_{0}+I_{1}+I_{2}\right) / 3$ where $G_{0}, G_{1}, G_{2}$ and $I_{0}$, $I_{1}, I_{2}$ are blood glucose and serum insulin levels, respectively, at 0,1 , and $2 \mathrm{~h}$ after oral glucose load. Serum calcium was determined by atomic absorption spectrophotometry (Varian Techtron Model 1000, Zug, Switzerland), while estimations of serum phosphorus and cholesterol were done by the methods of Chen et al. [10] and Watson [11], respectively.

Data obtained before and after administration of vitamin $\mathrm{D}$ were analyzed statistically by the paired ' $t$ ' test. 


\section{RESULTS}

All the subjects had impaired oral glucose tolerance before the administration of vitamin D, despite being on their usual medical treatment regimen (Fig. 1).

Intramuscular injection of vitamin D (300,000 IU) did not have any apparent adverse or toxic effects. On the other hand, all the subjects experienced a general feeling of physical well-being after the injection.

Improvement was observed in oral glucose tolerance in NIDDM patients (Fig. 1: Panel A) as well as in IDDM patients (Fig. 1: Panel B), when the test was given 4 weeks after vitamin $\mathrm{D}$ injection. This is also evident from the values of total blood glucose $(\mathrm{mg} / \mathrm{dl})$ before/after treatment with vitamin $\mathrm{D}$, which were $291 \pm$ $18.3 / 242 \pm 14.2$ and $321 \pm 23.7 / 236 \pm 27.8$ (Mean \pm SEM), respectively, for NIDDM and IDDM patients. The improvement was statistically significant $(p<0.001)$ in NIDDM patients; while it missed statistical significance in IDDM patients, perhaps due to the smaller sample size.

Fasting serum insulin levels were raised, though not significantly, 4 weeks after vitamin D injection in the NIDDM group. However, after vitamin D administration, there was a significant $(p<0.05)$ increase in glucose-stimulated insulin secretion, both at 1 and $2 \mathrm{~h}$ after the oral glucose load (Fig. 2). This is also reflected in a significantly higher $(p<0.05)$ total serum insulin level $(23.9 \pm 2.13$

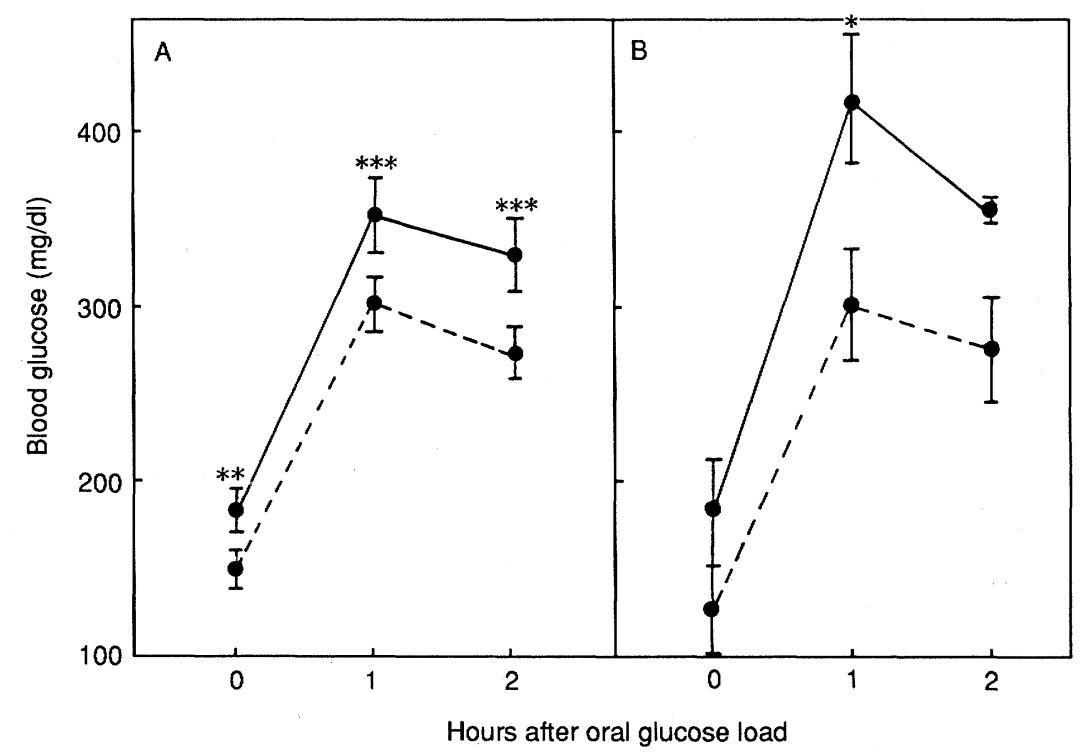

Fig. 1. Oral glucose tolerance of NIDDM ( $n=42$; Panel A) and IDDM ( $n=6$; Panel B) patients before (solid line) and 4 weeks after (broken line) administration of a single intramuscular injection of vitamin D $(300,000 \mathrm{IU}) .{ }^{*} p<0.05 ;{ }^{* *} p<0.01$, and ${ }^{* * *} p<0.001$ by paired ' $t$ ' test, before vs. after treatment with vitamin $\mathrm{D}$. 


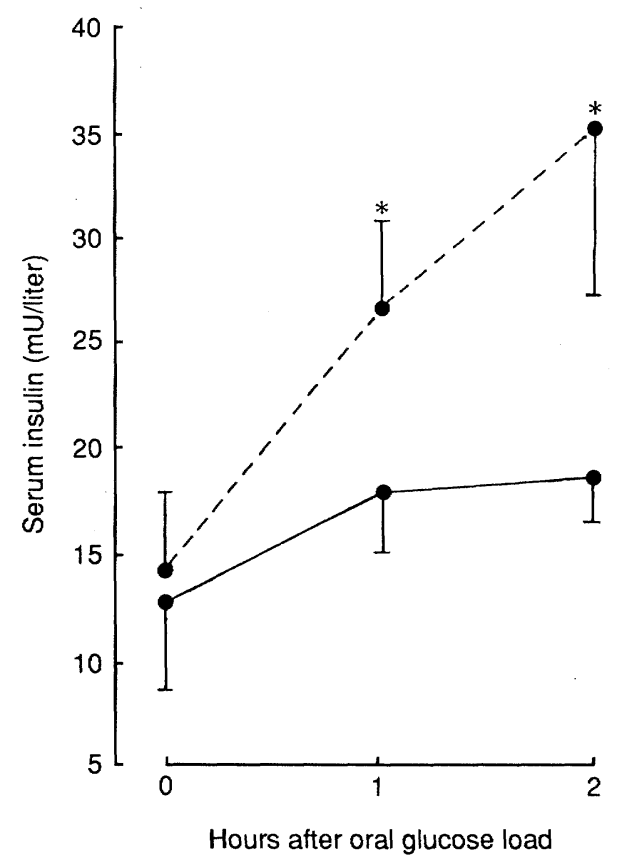

Fig. 2. Serum insulin levels (mU/liter) of diabetic (NIDDM) patients before (solid line) and 4 weeks after (broken line) administration of vitamin D. Basal and glucosestimulated insulin levels are shown. ${ }^{*} p<0.05$ by paired ' $t$ ' test, before vs. after treatment with vitamin $\mathrm{D}(n=6)$.

Table 1. Levels of calcium, phosphorus, and cholesterol in sera of diabetic patients before and after administration of vitamin D.

\begin{tabular}{|c|c|c|c|c|c|c|c|}
\hline & \multirow{3}{*}{$n$} & \multicolumn{2}{|c|}{ Calcium } & \multicolumn{2}{|c|}{ Phosphorus } & \multicolumn{2}{|c|}{ Cholesterol } \\
\hline & & Before & After & Before & After & Before & After \\
\hline & & \multicolumn{2}{|c|}{$(\mathrm{mg} / \mathrm{dl})$} & \multicolumn{2}{|c|}{$(\mathrm{mg} / \mathrm{dl})$} & \multicolumn{2}{|c|}{$(\mathrm{mg} / \mathrm{dl})$} \\
\hline NIDDM & 42 & $8.6 \pm 0.11$ & $9.2 \pm 0.10^{* * *}$ & $4.1 \pm 0.20$ & $3.4 \pm 0.16^{* * *}$ & $245 \pm 11.4$ & $232 \pm 10.6^{* *}$ \\
\hline IDDM & 6 & $8.5 \pm 0.58$ & $9.2 \pm 0.36$ & $4.4 \pm 0.28$ & $3.2 \pm 0.08^{*}$ & $253 \pm 20.1$ & $235 \pm 20.9$ \\
\hline
\end{tabular}

$\mathrm{mU} /$ liter) after vitamin $\mathrm{D}$ injection, than before $(16.4 \pm 1.62 \mathrm{mU} /$ liter) (Mean \pm SEM).

In NIDDM patients, vitamin D administration significantly improved serum calcium $(p<0.01)$ and lowered serum phosphorus $(p<0.001)$ and cholesterol $(p<$ $0.02)$. Although the effects of vitamin $D$ were similar in IDDM patients, the change in serum phosphorus was statistically significant $(p<0.05)$, but that in the other parameters was not, perhaps due to the smaller sample size. 


\section{DISCUSSION}

The present study has demonstrated unequivocally improvement in oral glucose tolerance by a single intramuscular injection of vitamin D $(300,000 \mathrm{IU})$, in uncontrolled diabetic patients of both IDDM and NIDDM type. This, to our knowledge, is the first such demonstration in humans, although abundant direct and indirect evidence is available in experimental animals for such an effect of vitamin $D$. It is interesting to note that vitamin $\mathrm{D}$ had beneficial effects in both NIDDM and IDDM patients.

Despite evidence in experimental animals of impaired insulin secretion, glucose intolerance, and hypocalcemia in vitamin D deficiency [3, 12-14], no such evidence exists in humans. In the present study the subjects had marginal hypocalcemia: serum calcium levels were: $8.5 \pm 0.58$ and $8.6 \pm 0.11$ (mean \pm SEM) in IDDM and NIDDM, respectively. Vitamin D administration resulted in significant improvement in serum calcium levels and lowering of serum phosphorus and cholesterol besides the significant improvement in oral glucose tolerance. The nature of association between vitamin $\mathrm{D}$ status and glucose tolerance in human diabetics observed in the present study appears analogous to that seen in psoriasis $[15,16]$. The beneficial effects of vitamin D on skin lesions have been demonstrated, although vitamin $\mathrm{D}$ deficiency per se has not been shown to be involved in the etiology of psoriasis.

The mechanism by which vitamin $\mathrm{D}$ administration improves glucose tolerance is not very clear yet. Improved levels of serum $\mathrm{Ca}$ in the presence of possibly higher levels of $1,25(\mathrm{OH})_{2} \mathrm{D}$ due to vitamin $\mathrm{D}$ administration could raise the cytosolic calcium of islets, which in turn could result in increased release of insulin $[17,18]$. Interestingly, receptors for $1,25(\mathrm{OH})_{2} \mathrm{D}$ have been demonstrated in the cytosol and nuclei of $\beta$-cells of islets $[19,20]$. Also, immunoreactive vitamin D-dependent calcium-binding protein has been shown in these cells [21] and dietary vitamin $\mathrm{D}$ or $1,25(\mathrm{OH})_{2} \mathrm{D}$ has been demonstrated to be essential for normal insulin secretion $[22,23]$. The fact that we have observed, in the present study, increased levels of serum calcium and insulin in subjects given vitamin D may bear testimony that this is probably one of the mechanisms. Nyomba et al. [7] and Cade and Norman [12] demonstrated in vitamin D-deficient rabbits and rats that increasing serum calcium levels by infusion or through the dietary route did not correct the impaired glucose tolerance or insulin secretion. This may be because of the lack of vitamin $\mathrm{D}$, vis-a-vis $1,25(\mathrm{OH})_{2} \mathrm{D}$, which is essential to increase the cytosolic calcium of islets, by interacting with its specific receptors $[19,20]$. Taken with these observations, the results of the present study provide a clear demonstration that maintenance of normal or raised serum calcium alone may not ensure increased glucose-stimulated insulin secretion unless circulating levels of $1,25(\mathrm{OH})_{2} \mathrm{D}$ are adequate.

It is possible that vitamin $\mathrm{D}$ may also be acting through mechanisms other 
than through its effect on calcium homeostasis. Steroids (glucocorticoids) are known to be among the 'nonglucose' type of modulators of insulin secretion [24]. Evidence is also available showing no impairment in insulin response to nonglucose secretagogues in NIDDM patients, although acute insulin response to glucose is impaired $[25,26]$. In the present study the slightly higher basal levels of serum insulin in subjects given vitamin $\mathrm{D}$, a secosteroid, could perhaps be due to the nonglucose secretagogue-like effect of vitamin $\mathrm{D}$ and/or its metabolite on the $\beta$-cell.

The action of $1,25(\mathrm{OH})_{2} \mathrm{D}$ is like that of a steroid hormone, and may thus alter the membrane characteristics and function $[27,28]$. Further, the high- $K_{\mathrm{m}}$ glucose transporter (Glut 2), an islet membrane protein which plays important role in glucose uptake by islets, has been shown to be underexpressed in NIDDM [29]. It appears probable that $1,25(\mathrm{OH})_{2} \mathrm{D}$, acting like a steroid hormone, could alter glucose uptake and also Glut 2 function, in islet membranes in NIDDM. In IDDM, on the other hand, peripheral tissue uptake and utilization of glucose may be affected. However, the exact mechanism by which vitamin $\mathrm{D}$ manifests its beneficial effects in IDDM is not clear at present.

The authors acknowledge the encouragement received from Dr. Vinodini Reddy, Director, National Institute of Nutrition, Hyderabad, in the conduct of these studies. Thanks are due to Mrs. C. Maniprabha and Mr. S. Chennaiah for their skillful technical assistance and to Sri M.M. Khan for the calcium determinations made by atomic absorption spectrophotometry.

\section{REFERENCES}

1. Albright, E., and Reifenstein, E.C. (ed.) (1948): Parathyroid Glands and Metabolic Bone Disease: Selected Studies, Williams \& Wilkins Company, Baltimore, $150 \mathrm{pp}$.

2. Levin, M.E., Biosseau, V.C., and Avioli, L.V. (1976): Effect of diabetes mellitus on bone mass in juvenile and adult onset diabetes. N. Engl. J. Med., 294, 241-245.

3. Yasuda, K. (1980): Hyperglycemia caused by hypocalcemia or calcium depletion in secondary diabetes, in The Spectrum of Diabetic Syndromes, ed. by Podosky, S. and Viswanathan, M.T., Raven Press, New York, pp. 449-464.

4. Norman, A.W., Frankel, B.J., Heldt, A.M., and Grodsky, G.M. (1980): Vitamin D deficiency inhibits pancreatic secretion of insulin. Science, 209, 823-825.

5. Chertow, B.S., Sivitz, W.I., Baranetsky, N.G., Clark, S.A., Waite, A., and DeLuca, H.F. (1983): Cellular mechanisms of insulin release: The effect of vitamin D deficiency and repletion on rat insulin secretion. Endocrinology, 113, 1511-1518.

6. Cade, C., and Norman, A.W. (1987): Rapid normalization/stimulation by 1,25-dihydroxyvitamin $\mathrm{D}_{3}$ of insulin secretion and glucose tolerance in the vitamin $\mathrm{D}$ deficient rat. Endocrinology, 120, 1490-1497.

7. Nyomba, B.L., Bouillon, R., and Moor, P.D. (1984): Influence of vitamin D status on insulin secretion and glucose tolerance in the rabbit. Endocrinology, 115, 191-197.

8. World Health Organization (1985): Diabetes Mellitus, Technical Report Series 727, p. 99

9. Ashwell, G. (1957): Colorimetric analysis of sugars, in Methods in Enzymology, Vol. 3, ed. by Colowick, S.P. and Kaplan, N.O., Academic Press, New York, pp. 73-105.

10. Chen, P.S., Jr., Toribara, T.Y., and Warner, H. (1956): Microdetermination of phosphorus. Anal. Chem., 28, 1756-1758.

11. Watson, D. (1960): A simple method for the determination of serum cholesterol. Clin. Chim. 
Acta, 5, 637-643.

12. Cade, C., and Norman, A.W. (1986): Vitamin $D_{3}$ improves impaired glucose tolerance and insulin secretion in the vitamin D deficient rat in vivo. Endocrinology, 119, 84-90.

13. Schneider, L.E., and Schedl, H.P. (1977): Experimental diabetes reduces circulating 1,25-dihydroxy vitamin D in the rat. Science, 196, 1452-1454.

14. Tanaka, Y., Seino, Y., Ishida, M., Yamaoka, K., Satomura, K., Satomura, K., Yabuuchi, H., Seino, Y., and Imura, H. (1986): 1,25-Dihydroxy vitamin $\mathrm{D}_{3}$ on insulin secretion: Direct or mediated? Endocrinology, 118, 1971-1976.

15. MacLaughlin, J.A., Gange, W., Taylor, D., Smith, E.L., and Hollick, M.F. (1985): Cultured psoriatic fibroblasts from involved and uninvolved sites have a partial but not absolute resistance to proliferation inhibition activity of 1,25 -dihydroxy vitamin $\mathrm{D}_{3}$. Proc. Natl. Acad. Sci., 82, 5409-5412.

16. Holick, M.F. (1989): 1,25-Dihydroxy vitamin $D_{3}$ and the skin: A unique application for the treatment of psoriasis. Proc. Soc. Exp. Biol. Med., 191, 246-257.

17. Wollhein, C.B., and Sharp, G.W.C. (1981): Regulation of insulin release by calcium. Physiol. Rev., 61, 914-973.

18. Clark, S.A., Stumpf, W.E., and Sar, M. (1981): Effect of 1,25-dihydroxy vitamin $D_{3}$ on insulin secretion. Diabetes, 30, 382-386.

19. Christakow, S., and Norman, A.W. (1981): Studies on the mode of action of calciferol XXIX. Biochemical characterization of 1,25-dihydroxy vitamin $\mathrm{D}_{3}$ receptors in chick pancreas and kidney cytosol. Endocrinology, 108, 140-149.

20. Narbaitz, R., Stumpf, W.E., and Sar, M. (1981): The role of autoradiographic and immunocytochemical techniques in the clarification of sites of metabolism and action of vitamin D. J. Histochem. Cytochem., 29, 91-98.

21. Roth, J., Bonner-Weir, S., Norman, A.W., and Orci, L. (1982): Immunocytochemistry of vitamin D-dependent calcium binding protein in chick pancreas: Exclusive localization in B-cells. Endocrinology, 110, 2216-2218.

22. Kadowaki, S., and Norman, A.W. (1984): Dietary vitamin D is essential for normal insulin secretion from the perfused rat pancreas. J. Clin. Invest., 73, 759-766.

23. Kadowaki, S., and Norman, A.W. (1985): Time course study of insulin secretion after 1,25-dihydroxy vitamin $\mathrm{D}_{3}$ administration. Endocrinology, 117, 1765-1771.

24. Marco, J., Cale, C., Roman, D., Dizadiaz-Fierros, M., Vallanueva, M.L., and Valverde, I. (1973): Hyperglucagonism induced by glucocorticoid treatment in man. N. Engl. J. Med., 288, $128-131$.

25. Palmer, J.P., Bensen, J.W., Walter, R.M., and Ensinck, J.W. (1976): Arginine stimulated acute phase of insulin and glucagon secretion in diabetic subjects. J. Clin. Invest., 58, 565570.

26. Cerasi, E., Inft, R., and Efendic, S. (1972): Decreased sensitivity of the pancreatic $\beta$-cells to glucose in pre-diabetic and diabetic subjects: A glucose dose-response study. Diabetes, 21, 224-234.

27. Wilson, P.W., and Lawson, D.E.M. (1977): 1,25-Dihydroxy vitamin $\mathrm{D}_{3}$ stimulation of specific membrane proteins in chick intestine. Biochim. Biophys. Acta, 497, 805-811.

28. Haussler, M.R., Naogde, L.A., and Rasmussen, H. (1990): Induction of intestinal brush border alkaline phosphatase by vitamin D and identity with Ca-ATPase. Nature, 228, 11991201.

29. Johnson, J.H., Ogawa, A., Chen, L., Orci, L., Newgard, C.B., Alam, T., and Unger, R.H. (1990): Underexpression of $\beta$-cell high $K_{\mathrm{m}}$ glucose transporters in noninsulin-dependent diabetes. Science, 250, 546-549. 